Journal of

Literary Education

\title{
Donkey Xote cabalga distinto en España y en Italia: reflexiones sobre la intertextualidad audiovisual
}

\author{
Donkey Xote ride differently in Spain and in Italy: \\ considerations about audiovisual intertextuality
}

\section{Donkey Xote cavalca distint a Espanya i Itàlia: reflexions sobre la intertextualitat audiovisual}

Mercedes Ariza. Fondazione Universitaria San Pellegrino, Italia, mercedes.ariza@fusp.it

(iD) https://orcid.org/0000-0002-3699-9229

How to cite this paper:

Ariza, Mercedes (2018). Donkey Xote cabalga distinto en España y en Italia: reflexiones sobre la intertextualidad audiovisual. Journal of Literary Education, (1), 58-78. https://doi.org/10.7203/JLE.1.12085 